\title{
Sexagem de espermatozoides bovinos por centrifugação em gradiente descontínuo de densidade de Percoll ${ }^{1}$
}

\author{
Vera Fernanda Martins Hossepian de Lima ${ }^{2}$, Carlos Alberto Moreira-Filho ${ }^{3}$, Aline Costa de \\ Lucio $^{3}$, Max Vitória Resende 3
}

\author{
1 Pesquisa financiada pela FAPESP processo $n^{\circ}$ 96/1379-2. \\ 2 Departamento de Medicina Veterinária Preventiva e Reprodução Animal, FCAV, Unesp, 14884-900, Jaboticabal, SP \\ ${ }^{3}$ Departamento de Imunologia, ICB, USP, 05088-900, São Paulo, SP.
}

RESUMO - O objetivo neste trabalho foi desenvolver um método de seleção do sexo de espermatozoides bovinos por centrifugação em gradiente de densidade de Percoll. Utilizou-se sêmen congelado de touros mantidos em regime de colheita de sêmen. A fração de espermatozoides X ou Y foi separada por centrifugação em treze diferentes gradientes de densidade de Percoll formados por 1 a 12 camadas com densidades que variaram de $1,004 \mathrm{~g} / \mathrm{mL}$ a 1,123 g/mL. As soluções com diferentes densidades foram preparadas misturando-se, em proporções diferentes, meio de cultura Hank's e uma solução estoque composta de $\mathrm{NaCl} 1,5 \mathrm{M}$ e Percoll $(1: 9, \mathrm{v} / \mathrm{v})$. Sobre cada gradiente foi colocado um total de $50 \times 10^{6}$ espermatozoides descongelados em $0,7 \mathrm{~mL}$ de meio Hank's e centrifugados a $250 \mathrm{X}$ g por 30 minutos, em rotor horizontal, a $25^{\circ} \mathrm{C}$. Os espermatozoides das frações superior e inferior foram tratados com Quinacrina Mustarda e analisados (200 deles) quanto à presença do corpúsculo-F. Dos espermatozoides encontrados no sedimento de dois gradientes, compostos de 8 e 12 frações com densidades variando entre 1,050 a $1,120 \mathrm{~g} / \mathrm{mL}$ e 1,044 a $1,123 \mathrm{~g} / \mathrm{mL}$, respectivamente, visualizaram-se $25 \%$ com corpúsculo-F e os $75 \%$ restantes prováveis portadores do cromossomo X. O aumento na porcentagem de espermatozoides $\mathrm{X}$ após a centrifugação em gradiente de densidade permitirá que esse método de sexagem seja usado em larga escala na produção comercial de carne e leite bem como no teste de progênie.

Palavras-chave: Bos taurus, seleção do sexo, sêmen

\section{Sex selection in bovine spermatozoa by using Percoll discontinuos density gradient centrifugation}

\begin{abstract}
The objective of this work was to develop a bovine spermatozoid sex selection method by using Percoll density gradient centrifugation. It was used frozen semen of bulls kept in semen collection regime. Fraction X or Y was separated by centrifugation in three different Percoll density gradient formed by 1 to 12 layers with densities varying from $1.004 \mathrm{~g} / \mathrm{mL}$ to $1.123 \mathrm{~g} / \mathrm{mL}$. Solutions with different densities were prepared by mixing, at different proportions, Hank's culture medium and a stock solution composed of $\mathrm{NaCl} 1.5 \mathrm{M}$ and Percoll $(1: 9, \mathrm{v} / \mathrm{v})$. On each gradient, it was put $50 \times 10^{6}$ spermatozoids thawed in Hank's medium and centrifuged at $250 \mathrm{X} \mathrm{g}$ for $30 \mathrm{~min}$ in a horizontal rotor, at $25^{\circ} \mathrm{C}$. The spermatozoids in the superior and inferior fractions were treated with Mustard Quinacrine and analyzed (200 spermatozoids) for the presence of F-body. Of the spermatozoids found in the sediment of the two gradients, composed of 8 and 12 fractions with densities varying from 1.050 to $1.120 \mathrm{~g} / \mathrm{mL}$ and 1.044 to $1.123 \mathrm{~g} / \mathrm{mL}$, respectively, it was identified $25 \%$ with the F-body and the other $75 \%$ were probably $\mathrm{X}$ chromosome-bearing spermatozoids. Increase in percentage of the $\mathrm{X}$-spermatozoid after density gradient centrifugation will allow this system of spermatozoid sexing to be used in large scale in commercial production of meat and milk as well as for progeny tests in bovines.
\end{abstract}

Key Words: Bos taurus, semen, sex selection

\section{Introdução}

A sexagem de espermatozoides tem valor econômico significativo nos animais de interesse zootécnico com aptidão para produção de leite ou carne e em sistemas em que a produtividade é favorecida pela progênie de um dos sexos (Taylor et al., 1985; Van Vleck et al., 1987; Ruvuna et al., 1992; Hohenboken, 1999).

Há no mercado demanda por uma tecnologia de seleção do sexo de espermatozoides que possa ser inserida na indústria de produção de sêmen congelado. O ideal seria que essa inovação não comprometesse a viabilidade 
espermática, pudesse ser utilizada em espermatozoides descongelados (para a utilização de sêmen de touros que não tiveram os seus espermatozoides sexados) e na produção de várias doses de sêmen enriquecido, com acuidade mínima de $70 \%$, congelado por dia, agregando valor máximo de US\$10 a 20 por dose (Hohenboken, 1999).

A morfologia do par de cromossomos sexuais e, consequentemente o conteúdo de DNA, foi a única diferença estabelecida e validada cientificamente em que se pôde basear o desenvolvimento de métodos para a separação eficiente de espermatozoides $\mathrm{X}$ ou $\mathrm{Y}$ in vitro (Johnson, 1994; Hendriksen et al., 1999). Em bovinos, a diferença no conteúdo de DNA foi quantificada em 4,0\% (Garner et al., 1983; Johnson et al., 1987; Johnson, 1992) e a diferença de densidade de $0,06 \%$ entre os espermatozoides $\mathrm{X}$ ou Y (Windsor et al., 1993). Com base nesta diferença, dois métodos foram desenvolvidos para a seleção do sexo dos espermatozoides: a citometria de fluxo e a centrifugação em gradiente de densidade.

Embora com bons resultados na separação espermática, a citometria de fluxo é pouco eficiente em relação ao investimento com o equipamento e pela baixa produção/ equipamento/hora, que nãoultrapassa $12 \times 10^{6}$ espermatozoides em alta velocidade de separação (Johnson \& Welch, 1999), restringindo sua utilização na indústria da inseminação artificial. Esse quadro é agravado pelo fato de que o sêmen de alguns deles não resiste ao processo de sexagem por essa técnica ou produzem variações na taxa de clivagem (0 a 89\%) e na taxa de blastocistos produzidos por oócitos (3,5 a 28,8\%) (Palma et al., 2008).

Na produção in vitro de embriões, obtém-se $45 \%$ de prenhez utilizando sêmen convencional. Com a utilização de sêmen sexado, sem submetê-los a congelação, na produção in vitro de embriões, obtém-se $66 \%$ de clivagem e 16 a $20 \%$ de desenvolvimento (Guthrie et al., 2002). Na inseminação artificial, a taxa de prenhez variou de 21 a $48 \%$, enquanto utilizando espermatozoides não-sexados as taxas foram 32\% a 68\% (Bodmer et al., 2005; Andersson et al., 2006; Siedel \& Schenk, 2008). Considerando esses resultados, torna-se evidente que os espermatozoides sexados por citometria de fluxo comprometem a taxa de gestação e estratégias para a aplicação comercial in vivo desse sêmen deveriam ter como foco caminhos para se obter um benefício efetivo, incluindo idade à primeira parição, frente ao custo de utilização (Weigel, 2004).

O objetivo com este trabalho foi desenvolver um método de seleção do sexo de espermatozoides por centrifugação em gradiente de densidade de Percoll na separação de espermatozoides portadores do cromossomo X ou Y em bovinos (Hossepian de Lima et al., 2003 BR PI 0300604-2).

\section{Material e Métodos}

Foram utilizadas 1.040 doses de sêmen congelado de 12 touros Bos taurus ( 3 de cada uma das seguintes raças: Aberdeen Angus, Holandês, Limousin e Simental) e 10 Bos indicus ( 3 da raça Gir leiteiro, 3 da raça Nelore, 2 da raça Nelore Mocha e 2 da raça Tabapuã). Os touros foram escolhidos entre aqueles em que cada dose de sêmen descongelado apresentava $30 \times 10^{6}$ espermatozoides vivos e mantidos na central de colheita e comercialização de sêmen.

Na central, cada um dos 22 touros teve o seu primeiro e segundo ejaculados colhidos com vagina artificial e o sêmen foi diluído e congelado de acordo com a rotina da empresa.

Para utilização neste trabalho, preparou-se uma solução estoque diluindo-se 11 partes de Percoll (densidade padrão de $1,130 \mathrm{~g} / \mathrm{mL})$ em 1 parte de $\mathrm{NaCl} 1,5 \mathrm{M}(1: 11, \mathrm{v} / \mathrm{v})$, contendo 5,55 mM de glicose, $2 \mathrm{mM}$ de HEPES (H0763, Sigma) e $10 \mathrm{mg}$ de kanamicina/mL; $\mathrm{pH} 7,4 ; 280-290 \mathrm{mOsm} / \mathrm{kg} \mathrm{H}_{2} \mathrm{O}$. A solução de $\mathrm{NaCl} 1,5 \mathrm{M}$ foi preparada com água bidestilada, filtrada em membrana com poros de $0,22 \mu$ e estocada a $4^{\circ} \mathrm{C}$ por períodos que não ultrapassaram dez dias. $\mathrm{O} \mathrm{pH}$ foi ajustado utilizando-se solução de ácido acético glacial a 1\% ou $\mathrm{NaOH} 1 \mathrm{~N}$.

Prepararam-se soluções isotônicas $(280 \mathrm{mOsm} / \mathrm{kg})$ de Percoll com diferentes densidades diluindo-se a solução estoque em meio Hank's. O gradiente descontínuo de Percoll foi preparado depositando-se $0,7 \mathrm{~mL}$ de cada uma das soluções, da mais densa para a menos densa, em tubos cônicos de poliestireno, com auxílio de uma pipeta.

Foram testados 13 gradientes constituídos das seguintes densidades (g/mL): Gradiente 1 (G1): 1,052; 1,063; 1,$075 ; 1,085 ; 1,122$; Gradiente 2 (G2): 1,004; 1,062; 1,064; 1,$066 ; 1,068 ; 1,070 ; 1,080$; Gradiente 3 (G3): 1,034; 1,057; 1,068; 1,080; 1,094; 1,1028; Gradiente 4 (G4): 1,043; 1,063; 1,065; 1,074; 1,1294; Gradiente 5 (G5): 1,020; 1,048; 1,062; 1,075; 1,088; Gradiente 6(G6): 1,110; Gradiente 7(G7): 1,070; 1,080; 1,090; 1,100; Gradiente 8 (G8): 1,050; 1,060; 1,070; 1,$080 ; 1,090 ; 1,100 ; 1,110 ; 1,123$; Gradiente 9 (G9): 1,004 ; 1,$062 ; 1,064 ; 1,066 ; 1,068 ; 1,070 ; 1,080 ;$ Gradiente $10(\mathrm{G} 10)$ : 1,$049 ; 1,057 ; 1,064 ; 1,071 ; 1,079 ; 1,088 ; 1,094 ; 1,097 ; 1,123$; Gradiente 11 (G11): 1,049; 1,050; 1,058; 1,063; 1,068; 1,073; 1,092; 1,097; 1,123; Gradiente 12 (G12): 1,044; 1,051; 1,058; 1,$064 ; 1,071 ; 1,077 ; 1,084 ; 1,090 ; 1,097 ; 1,103 ; 1,109 ; 1,123$; Gradiente 13(G13): 1,034; 1,038; 1,042; 1,045; 1,049; 1,053; 1,$057 ; 1,060 ; 1,064 ; 1,068$.

Dentro de cada subespécie, uma dose $(0,5 \mathrm{~mL})$ do sêmen descongelado de um touro de cada raça foi misturada na tentativa de retirar os possíveis efeitos dos indivíduos 
e das raças. Assim, obtinham-se 5 e $6 \mathrm{~mL}$ de sêmen descongelado de touros Bos indicus e Bos taurus, respectivamente.

Após a mistura, foi retirada uma alíquota de $5 \mu \mathrm{L}$ e outra de $100 \mu \mathrm{L}$ para avaliação da concentração e da motilidade dos espermatozoides, respectivamente. Cada 2 $\mathrm{mL}$ do restante da mistura de espermatozoides foram depositados sobre $2 \mathrm{~mL}$ de solução de Percoll a $80 \%$ (Gradiente G6) contida em um tubo cônico de poliestireno e centrifugado a $250 \mathrm{X}$ g por 30 minutos, em rotor horizontal. O sobrenadante, que se constituía do diluidor e dos espermatozoides inviáveis, foi desprezado. O sedimento de espermatozoides foi ressuspenso em 0,7 a 1,5 $\mathrm{mL}$ de meio de cultura Hank's (H1387, Sigma) sem bicarbonato de sódio e contendo 5,55 mM de glicose, $2 \mathrm{mM}$ de HEPES (H0763, Sigma), 0,1 g/mL de BSA (A8806) e $10 \mu \mathrm{g} / \mathrm{mL}$ de kanamicina; $\mathrm{pH} 7,4$. Este meio foi preparado com água bidestilada, filtrado em membrana com poros de $0,22 \mu \mathrm{e}$ estocado a $4^{\circ} \mathrm{C}$ por períodos que não ultrapassaram 10 dias. $\mathrm{O}$ pH foi ajustado utilizando-se solução de ácido acético glacial a $1 \%$ ou $\mathrm{NaOH} 1 \mathrm{~N}$.

O sedimento ressuspenso em Hank's foi submetido à centrifugação em gradiente de Percoll na tentativa de separar a fração de espermatozoides portadores do cromossomo X daquela portadora do cromossomo Y.

Um total de $5 \times 10^{7}$ espermatozoides contidos em 0,7-1,5 mL de meio de cultura Hank's, foram depositados sobre cada um dos 13 gradientes, mantidos a $25^{\circ} \mathrm{C}$ e centrifugados a $250 \mathrm{Xg}$ por 30 minutos, em rotor horizontal. A suspensão de espermatozoides foi separada nas frações superior e inferior. Como o espermatozoide $\mathrm{X}$ tem maior densidade devido ao maior conteúdo de DNA espera-se que a velocidade de sedimentação através do gradiente seja maior que a do cromossomo Y quando ambos são submetidos a mesma força centrífugas.

As frações superior e inferior (sedimento) foram aspiradas, lavadas em meio Hank's, centrifugadas a $500 \mathrm{X}$ g por 10 minutos e ressuspensas em $1 \mathrm{~mL}$ do mesmo meio. Para a verificação dos resultados, uma amostra $(0,2 \mathrm{~mL})$ das frações inferior e superior, foi colhida. Procederam-se a dez repetições de cada gradiente.

Para verificar a proporção de espermatozoides portadores do cromossomo $\mathrm{X}$ e portadores do cromossomo Y nas frações superior e inferior de cada gradiente, avaliou-se a presença do corpúsculo $\mathrm{F}$, que é a região distal do braço curto do cromossomo Y e pode ser observado como um ponto fluorescente, no centro ou na extremidade da cabeça do espermatozoide, a Quinacrina Mustarda (Pearson, 1972).
Cem microlitros da mistura inicial de espermatozoides (grupo controle) e $0,1 \mathrm{~mL}$ de cada fração (contendo espermatozoides portadores do cromossomo $\mathrm{X}$ ou $\mathrm{Y}$ ) foram transferidos para um microtubo $(50 \times 10 \mathrm{~mm})$. Em seguida, adicionou-se $0,1 \mathrm{~mL}$ de Dispase (Protease; 2000 P.U./mL extraída e purificada do Bacillus Polymixa; Godo Shusei Co. Ltd., Tokyo) e incubou-se a $37^{\circ} \mathrm{C}$ por 10 minutos. Adicionou-se 0,1 mL (concentração $0,05 \mathrm{mg} / \mathrm{mL}$ ) de Quinacrina Mustarda. Os microtubos foram colocados sob agitação por 60 minutos a temperatura ambiente.

Uma amostra de 0,002 $\mathrm{mL}$ de suspensão de células coradas com Quinacrina foi depositada no centro de uma lâmina para microscopia. Cada lâmina foi coberta com lamínula e analisada sob microscópio de fluorescência (BHS-RFS com filtro B excitador; 390 a $490 \mathrm{~nm}$ e filtro de suspensão ótica; $515 \mathrm{~nm}$ ). Foi usada uma lâmpada de mercúrio de alta pressão (VSH-200 MB) como fonte de luz e lentes objetivas de plano S 40x. Duzentas células foram analisadas de cada amostra e foi calculada a porcentagem de corpúsculos-F (Ogawa et al., 1988).

Os gradientes de densidade foram analisados por análise de variância (ANOVA) pelo método dos quadrados mínimos GLM (SAS, 2002), seguindo um delineamento inteiramente casualisado, em um esquema fatorial $2 \times 13$, sendo duas subespécies de bovinos e treze gradientes de densidade. As comparações múltiplas das médias foram realizadas pelo teste Tukey ao nível de significância de $(\mathrm{P}<0,05)$ de probabilidade.

\section{Resultados e Discussão}

Os valores de F para a porcentagem de espermatozoides Y nas frações superior e inferior (sedimento), em função do gradiente, comprovam que o gradiente teve efeito $(\mathrm{P}<0,05)$ na sexagem de espermatozoides (Tabela 1).

A interação da subespécie versus os gradientes demonstrou que os gradientes separaram os espermatozoides X ou Y com a mesma eficiência, independente da subespécie. A porcentagem média de espermatozoides $\mathrm{Y}$ na fração superior e no sedimento não diferiu significativamente considerando-se os resultados dos treze gradientes dentro de cada uma das subspécies.

Os gradientes G8 e G12 apresentaram, respectivamente, $74,38 \%$ e 74,73\% dos espermatozoides da fração superior eram portadores do cromossomo Y. No sedimento dos gradientes G8 e G12 observou-se 25,55\% e 25,45\%, respectivamente, de espermatozoides portadores do cromossomo Y (Tabela 2).

A recuperação dos espermatozoides $\mathrm{Y}$, que ficaram dispostos ao longo do gradiente de densidade, foi feita 
Tabela 1 - Valores de F, coeficiente de variação obtidos na análise de variância para identificação dos espermatozoides portadores do cromossomo Y nos gradientes de densidade

\begin{tabular}{lcc}
\hline Fontes de variação & $\begin{array}{c}\text { Espermatozoides Y na camada } \\
\text { superior do gradiente }\end{array}$ & $\begin{array}{c}\text { Espermatozoides Y na fração } \\
\text { inferior do gradiente }\end{array}$ \\
\hline F para subespécie & $0,15 \mathrm{~ns}$ & $0,10 \mathrm{~ns}$ \\
F para gradiente & $34,00^{* *}$ & $80,83^{* *}$ \\
F para interação subespécie $\times$ gradiente & $0,93 \mathrm{~ns}$ & $0,63 \mathrm{~ns}$ \\
Coeficiente de variação (\%) & 10,50 & 12,51 \\
\hline
\end{tabular}

ns - Não-significativo ao nível de $5 \%$ de probabilidade.

Valores na mesma linha com ** sobrescritos são diferentes pelo método dos quadrados míninos.

Tabela 2 - Médias obtidas na análise de variância para a identificação dos espermatozoides portadores do cromossomo Y nos gradientes de densidades testados

\begin{tabular}{ccc}
\hline Fontes de variação & $\begin{array}{c}\text { Espermatozoides Y na camada } \\
\text { superior do gradiente }\end{array}$ & $\begin{array}{c}\text { Espermatozoides Y na fração } \\
\text { inferior do gradiente }\end{array}$ \\
\hline Médias subespécie 1 (\%) & $61,14 \pm 10,09 \mathrm{a}$ & $47,8 \pm 12,91 \mathrm{a}$ \\
Subespécie 2 (\%) & $60,83 \pm 10,29 \mathrm{a}$ & $48,03 \pm 13,08 \mathrm{a}$ \\
Médias dos gradientes (\%) & & $52,10 \pm 3,8 \mathrm{c}$ \\
G1 & $55,13 \pm 3,78 \mathrm{de}$ & $63,80 \pm 8,18 \mathrm{a}$ \\
G2 & $65,43 \pm 8,58 \mathrm{~b}$ & $58,78 \pm 7,29 \mathrm{ab}$ \\
G3 & $64,00 \pm 7,6 \mathrm{bc}$ & $49,25 \pm 3,81 \mathrm{c}$ \\
G4 & $51,58 \pm 4,41 \mathrm{de}$ & $49,43 \pm 7,21 \mathrm{c}$ \\
G5 & $49,85 \pm 8,39 \mathrm{e}$ & $52,00 \pm 7,07 \mathrm{c}$ \\
G6 & $52,50 \pm 8,02 \mathrm{de}$ & $60,35 \pm 5,78 \mathrm{ab}$ \\
G7 & $62,30 \pm 5,46 \mathrm{bc}$ & $25,55 \pm 3,71 \mathrm{e}$ \\
G8 & $74,38 \pm 4,59 \mathrm{a}$ & $55,38 \pm 4,5 \mathrm{bc}$ \\
G9 & $57,70 \pm 5,85 \mathrm{~cd}$ & $39,25 \pm 4,36 \mathrm{~d}$ \\
G11 & $68,50 \pm 3,22 \mathrm{ab}$ & $41,50 \pm 6,93 \mathrm{~d}$ \\
G12 & $62,83 \pm 4,04 \mathrm{bc}$ & $25,45 \pm 4,19 \mathrm{e}$ \\
G13 & $74,73 \pm 7,32 \mathrm{a}$ & $50,15 \pm 7,34 \mathrm{c}$ \\
\hline
\end{tabular}

Valores com diferentes letras sobrescritas são diferentes $(\mathrm{P}<0,05)$ pelo método dos quadrados mínimos.

realizando uma centrifugação a $500 \mathrm{xg}$ por 10 minutos. Portanto, os gradientes G8 e G12 demonstram ser eficientes em separar espermatozoides X com acuidade de $74,45 \% \mathrm{e}$ $74,55 \%$, respectivamente.

A análise da porcentagem média de espermatozoides portadores de Y nas frações superior e inferior permitiu identificar três grupos distintos entre os 13 gradientes testados, quanto à eficiência na separação de espermatozoides portadores de X ou Y: grupo 1 - gradientes 1, 4, 5, 6, 9, 13 (baixa eficiência, em média 53,46\% de espermatozoides X); grupo 2 - gradientes 2, 3, 7, 10,11 (média eficiência, em média $64,61 \%$ de espermatozoides X); grupo 3 - gradiente 8,12 (alta eficiência, em média 74,5\% de espermatozoides X).

Os resultados demonstraram que a centrifugação de espermatozoides bovinos em gradientes compostos por 8 (gradiente 8) e 12 (gradiente 12) camadas de diferentes densidades foi eficiente na separação dos espermatozoides portadores de cromossomo X, com acuidade de $75 \%$. A repetibilidade foi de $70 \%$. A maior acuidade na separação dos espoermatozoides $\mathrm{X}$ pode estar relacionada à maior densidade do gradiente G8 maior densidade associada ao maior número de camadas do gradiente G12, que permitiram aos gradientes maior resolução (Windsor et al., 1993).

Hossepian de Lima et al. (2003), utilizando sêmen bovino in natura recém-colhido, desenvolveram um processo de separação dos espermatozoides $\mathrm{X}$, em gradientes de densidade descontínuos de Percoll com acuidade de entre 62 a 70\%. Na PIV de embriões a taxa de clivagem foi de $70 \%$ e de blastocisto de $25 \%$. Na inseminação artificial, obteve-se taxa de prenhez de até 75\%, com média de 70,7\% de fêmeas nascidas.

Apesar do menor índice de acuidade e repetibilidade, em relação ao método de citometria de fluxo, que atinge $90 \%$, o método desenvolvido apresentou as seguintes vantagens: a) possibilidade de recuperaração $12,5 \times 10^{6}$ ( $\cong 25 \%$ ), na fração inferior, dos $50 \times 10^{6}$ espermatozoides colocados sobre cada o gradiente. Como se centrifugava 16 gradientes a cada 30 minutos, produziram-se 32 doses de sêmen com $50 \times 10^{6}$ por hora (produção superior àquela de sete doses por hora conseguida pela técnica de citometria de fluxo); b) recuperação em todos os gradientes de $80 \%$ dos espermatozoides com motilidade. 
O método de verificação dos resultados escolhido foi o de coloração com quinacrina mustarda, como descrito por Ogawa et al. (1988), uma vez que é um método simples e rápido e permite o processamento e análise de todos os grupos experimentais e repetições no mesmo dia do experimento. Apesar de Ishijima et al. (1991) terem observado em seus experimentos que a coloração com quinacrina mustarda deu um erro de $16,4 \%$, Blottner et al. (1994) não observaram o mesmo quando compararam os resultados de seu experimento com aquele obtido por hibridização in situ.

A recuperação dos espermatozoides $\mathrm{Y}$ nos gradientes G8 e G12 foi de 5\%, uma vez que os espermatozoides se encontravam espalhados ao longo do gradiente.

Na produção animal, a separação dos espermatozoides $\mathrm{X}$ e $\mathrm{Y}$ é uma rota tecnológica promissora, pois permite a seleção do sexo por ocasião da inseminação artificial, técnica bastante difundida comercialmente. Entretanto, sua aplicabilidade comercial depende do estabelecimento de uma metodologia simples, compatível com o processo de congelação e que permita: a) processar várias amostras diariamente, a um custo baixo (\$10 a \$20/dose; Van Vleck et al., 1981); b) reduzir a perda de espermatozoides durante o processo; c) diminuir o desvio da proporção do sexo, sem a redução do poder de fecundação dos espermatozoides ou causar a eles danos na ultraestrutura ou no complemento cromossômico.

Considerando esses aspectos, entende-se que o aprimoramento do método de centrifugação em gradiente de Percoll, principalmente quanto à acuidade, poderá tornar viável utilização comercial da sexagem de espermatozoides nos sistemas de produção de carne e leite bem como nos sistemas modernos de teste de progênie.

\section{Conclusões}

Os espermatozoides portadores do cromossomo $\mathrm{X}$ ou Y são separados por centrifugação em gradiente de Percoll com acuidade de até $75 \%$, com taxa de recuperação dos espermatozoides de $25 \%$. Os gradientes de Percoll separam os espermatozoides $\mathrm{X}$ ou $\mathrm{Y}$ com a mesma eficiência, independentemente da subespécie (Bos taurus taurus ou Bos taurus indicus). A porcentagem média de espermatozoides portadores do cromossomo $\mathrm{Y}$, nas frações superior e inferior, permite identificar gradientes de alta, média e baixa eficiência de sexagem.

\section{Agradecimentos}

À FAPESP (Fundação de Amparo à Pesquisa do Estado de São Paulo), pelo suporte financeiro para o depósito da Patente BR PI 0300604-2, em 17 de junho de 2003.

\section{Referências}

ANDERSSON, M.; TAPONEN, J.; KOMMEN, M. et al. Pregnancy rates in lactating Holstein-Friesian cows after artificial insemination with sexed sperm. Reproduction Domestic Animals, v.41, p.95-7, 2006.

BLOTTNER, S.; BOSTEDT, H.; MEWES, K. et al. Enrichment of bovine $\mathrm{X}$ and $\mathrm{Y}$ spermatozoa by free-flow eletroforesis. Journal of Veterinary Medicine. Series A., v.41, p.466-74, 1994.

BODMER, M.; JANETT, F.; HÄSSIG, M. et al. Fertility in heifers and cows after low dose insemination with sex-sorted and nonsorted sperm under filed conditions. Theriogenology, v.64, p.1647-1655, 2005.

COLlEU, D.; LESCOAT, D.; GOURANTON, J. Nuclear maturity of human spermatozoa selected by swim-up or by percoll gradient centrifugation procedures. Fertility and Sterility, v.65, p.160-164, 1996 .

GUTHRIE, H.D.; JONSHON, L.A.; GARRET, W.M. et al. Flow cytometric sperm sorting: Effects of varying laser power on embryo development in swine. Molecular Reproduction and Development, v.61, n.1, p.87-92, 2002.

HOHENBOKEN, W.D. Applications of sexed semen in cattle production. Theriogenology, v.52, p.1421-33, 1999.

HOSSEPIAN DE LIMA, V.F.M.; MOREIRA-FILHO, C.A.; RAMALHO, M.F.P.D.T. Processo de seleção do sexo de espermatozoides mamíferos e métodos de controle de qualidade de doses de sêmen sexado congelado. FAPESP/ UNESP/USP (Brasil). BR PI 0300604-2, 17 Jun. 2003.

ISHIJIMA, S.A.; OKUNO, M.; MOHRI, H. Zeta potential of human $\mathrm{X}$ - and $\mathrm{Y}$ - bearingh sperm. International Journal of andrology, v.14, p.340-7, 1991

JOHNSON, L.A.; WELCH, G.R. Sex selection: high-speed flow cytometric sorting of $\mathrm{X}$ and $\mathrm{Y}$ sperm for maximum efficiency. Theriogenology, v.52, p.1323-1342, 1999.

OGAWA, S.; YAMAKAWA, H.; YAMANOI, J. et al. Are fluorescen bodies of Y-spermatozoa detectable in common with mammalian species? Theriogenology, v.239, n.5, p.1083-89, 1988

PALMA, G.A.; OLIVIER, N.S.; NEUMÜLER, C.H. et al. Effects of sex-sorted spermatozoa on the efficiency of in vitro fertilization and ultrastructure of in vitro produced bovine blastocysts. Anatomia Histologia Embryologia, v.37, p.67-73, 2008.

PEARSON, P. The use of new staining techniques for human chromossome identification. Journal Medical Genetics, v.9, p. 264, 1972 .

RUVUNA, F.; TAYLOR, J.F.; WALTER, J.P. et al. Bioeconomic evaluation of embryo transfer in beef production systems: III. Embryo lines production bulls. Journal of Animal Science, v.70, p.1091-1097, 1992.

SEIDEL JUNIOR, G.E.; SCHENK, J.L. Pregnancy rates in cattle with cryopreserved sexed sperm: effects of sperm numbers per inseminate and site of sperm deposition. Animal Reproduction Science, v. 105, p.129-138, 2008.

STATISTICAL ANALYSES SYSTEM - SAS. User's guide. Cary: SAS Institute Inc., 2002. 1037p.

TAYLOR, C.S.; MOORE, A.J.; THIESSEN, R.B. et al. Food efficiency in traditional and sex controlled systems of beef production. Animal Production, v.40, p.401-440, 1985. 
TAYLOR St., C.S.; THIESSEN, R.B.; MOORE, A.J. Single sex beef cattle systems. In: SMITH, C.; KING, J.W.B.; McKAY, J.C. (Eds.). Exploting new technologies in animal breeding. Oxford: Oxford University Press, 1986. p.183-93.

VAN VLECK, L.D.; POLLAK, J.E.; BRANDFORD-OLTENACU, E.A. Genetics for the animal science. New York: W.H. Freeman, 1987. p.287-313.
WEIGEL, K.A. Exploring the role of sexed semen in dairy production systems. Journal Dairy Science, v.87 (E. Suppl.), E120-E130, 2004.

WINDSOR, D.P.; EVANS, G.; WHITE, I.G. Sex predetermination by separation of $\mathrm{X}$ and $\mathrm{Y}$ chromossome- bearing sperm: A review. Reproduction Fertility Development, v.5, p.155-171, 1993. 